University of Nebraska - Lincoln

DigitalCommons@University of Nebraska - Lincoln

Robert Katz Publications

Research Papers in Physics and Astronomy

$1-1-1989$

Robert Katz: A Biographical Sketch

M. Eugene Rudd

University of Nebraska-Lincoln, erudd@unl.edu

John F. Fowler

Gray Laboratory, Mount Vernon Hospital, Northwood, Middlesex HA6 2RN, U.K.

Follow this and additional works at: https://digitalcommons.unl.edu/physicskatz

Part of the Physics Commons

Rudd, M. Eugene and Fowler, John F., "Robert Katz: A Biographical Sketch" (1989). Robert Katz Publications. 79.

https://digitalcommons.unl.edu/physicskatz/79

This Article is brought to you for free and open access by the Research Papers in Physics and Astronomy at DigitalCommons@University of Nebraska - Lincoln. It has been accepted for inclusion in Robert Katz Publications by an authorized administrator of DigitalCommons@University of Nebraska - Lincoln. 
Published in Nuclear Tracks and Radiation Measurements 16:2/3 (1989), pp. 83-85; now known as Radiation Measurements; formerly International Journal of Radiation Applications and Instrumentation. Part D. Nuclear Tracks and Radiation Measurements.

Published by 1989 Pergamon Press plc. Used by permission. http://www.sciencedirect.com/science/journal/13504487

\title{
Robert Katz: A Biographical Sketch
}

\author{
M. Eugene Rudd \\ Department of Physics and Astronomy, University of Nebraska-Lincoln, \\ Lincoln, NE 68588-0111, U.S.A. \\ John F. Fowler \\ Gray Laboratory, Mount Vernon Hospital, \\ Northwood, Middlesex HA6 2RN, U.K.
}

\section{Introduction}

Robert Katz was born in 1917 in New York City of Russian-Jewish immigrant parents. He grew up in the Bronx, attended Brooklyn College where he received his B.A. degree in 1937. A year later he was awarded the M.A. degree in physics at Columbia University. During World War II he worked for the Air Force at Wright Field in Ohio. After the war he returned to academia as a graduate student at the University of Illinois, where he earned the Ph.D. degree in physics in 1949. From that year he was a member of the Department of Physics at Kansas State University in Manhattan, Kansas, until 1966 when he joined the faculty at the University of Nebraska.

Anyone who knows Bob Katz knows that he is not one to be reticent in discussing his own work. One may even get the impression that he has exaggerated his achievements on one or two occasions. But when one examines the work of this talented and multi- faceted man, a solid record of accomplishments emerges. Nor are these all in a single field. Few people have brought a knowledge of physics to bear on so many areas of application, and not many have collaborated as effectively with colleagues in so many disciplines outside their own.

\section{Academic and Research Career}

As a university faculty member, Katz has always been an effective teacher and lecturer. His enthusiasm for his subject is contagious. He is able to get to the heart of a subject and express it with a clarity and forcefulness that commands attention. Part of his success as a teacher is being able to recognize from a student's poorly phrased question what the root of his or her difficulty is. In 1958 he co-authored a popular physics textbook with Henry Semat entitled Physics.

In 1962 Katz was named the outstanding faculty member at Kansas State University. He has been a visiting guest lecturer at Harvard's Summer School, and has taught at Columbia and at the Universities of Illinois and Connecticut.

In 1964 he wrote the book An Introduction to the Special Theory of Relativity for the Commission on College Physics. It became one of the Momentum Series published by Van Nostrand and was translated into Spanish, Polish, and Italian and was issued in a special Far Eastern edition. Francis Bitter, for whom the National Laboratory at M.I.T. is named, wrote to Katz in 1966 that after reading his book on special relativity he understood the subject for the first time. Comparing it to other books on the subject, he said "I find yours much the most useful because it is so clear and simple without evading any issues." High praise from a distinguished solid state physicist.

The book The New Professors edited by Robert O. Bowen and published by Holt, Harcourt \& Winston in 1960 gives a candid view of the academic profession as seen by "nine able young professors." Robert Katz was one of the nine chosen. Some of his strong and often controversial views of the educational establishment come through in his chapter in this book. For example, he concludes a description of his interactions with a Dean as follows: "All this discussion led to nothing, for we were operating from different premises: he from the notion that the faculty was to serve the administration, and I from the very opposite view." Or this view on the faculty: "With a built-in set of standards, a professor can enjoy his work. Without them, he spends his life jumping through other people's hoops."

From 1953 to 1957 Bob wrote the physics entries for the World Scope Encyclopedia Yearbooks. In these articles he summarized the developments in physics research during the previous years. Paragraphs with titles "Accelerators," "Solar Energy," "The Anti-Proton," "Radioastronomy," and "Refrigeration Near the Absolute Zero" indicate the breadth of his interests and knowledge. 
While a civilian physicist at Wright Field he designed the production model of the "pigtails" used on airplane wing tips to allow static charges to escape. Such charges, picked up when an airplane goes through rain or snow, cause interference, when they discharge, with radio communication. He also helped develop anti-static antennas and other hardware. His work on X-raying airplane parts for defects in the castings later led to the development of methods for X-raying grain to detect internal insect infestation. His methods received wide acceptance, and two companies, Westinghouse and General Electric, now manufacture $X$-ray units for this application which utilize his inspection technique. Katz holds three patents in these areas.

Bob worked with a number of people in the agriculture college at Kansas State on several projects. Besides introducing the method of soft X-ray radiography to detect internal insect infestation of grain, he also devised two methods for testing grain kernel density. One of these methods is the flotation of the grain in a column of liquid with a density gradient. The other method uses what he calls a "grain spectrometer." This involves projection of a sample of grain from a moving belt. The most dense samples land in a compartment far from the point of projection while those of smaller density are spread out in a "spectrum" in closer compartments. Other devices to measure grain hardness and mineral content also had their origin in the fertile mind of this man. If these methods do not seem to be especially innovative, consider these words from Sir Francis Bacon from about 350 years ago: "But such is the infelicity and unhappy disposition of the human mind in this course of invention, that it first distrusts and then despises itself: first [it] will not believe that any such thing can be found out; and when it was found out, cannot understand how the world should have missed it so long."

His teaching and textbook writing led to his interest in Dirac magnetic monopoles. Pedagogically, he felt that it was much easier to introduce electricity and magnetism through the use of electric charges and magnetic monopoles than through electric currents. This interest led to a paper [Phys. Rev. 116, 236 (1959)] proposing two new experiments for the detection of monopoles. Other papers dealt with the width of the tracks that monopoles would be expected to leave in emulsions and the response of plastics and other detectors to this hypothetical particle. Thus, the work on monopoles was a predecessor of Katz's later work on particle tracks, in which he is still active today.

In 1969 in collaboration with Mexican astronomer Arcadio Poveda and with Lewis Chadderton, a physicist from the North American Rockwell Corporation, Katz co-authored a paper entitled "Standing waves on the Moon" which was published in a prominent English science journal [Nature 223, 259 (1969)]. His key idea was that the moon has enough solidity that impacts on its surface could set up standing waves. The lunar patterns were taken to be the analog of Chladni figures, which are well known to physics teachers. There is evidence of this in the concentric rings around craters as well as in the fracture grid structure on the moon, both of which support this idea. A few months after the paper was published, the Apollo 12 lunar mission dropped a lunar module onto the surface of the moon and set up 30 minutes of seismic ringing, similar to what would be expected on the basis of this model. Walter Sullivan, the Science Editor of The New York Times, noted the Nature article's prediction in his news article on the event (The New York Times, November 27, 1969, p. 22C). Similar "Chladni figures" have now been observed on Callisto, one of Jupiter's moons.

At a university, professors are expected not only to teach and to do research, but also to perform service to the department, to the college, to the university, and to the larger community. Bob has not shirked his duties here either. On the departmental level, he served as Vice Chairman at the University of Nebraska under two department heads. During this time he was largely responsible for writing the proposal which led to an NSF Departmental Development grant of $\$ 750,000$ in 1969 . This grant, and the university support which followed, increased the number of members in Nebraska's Physics Department by about $50 \%$ in a relatively short time and also augmented the machine shop staff and the equipment budget. He not only wrote the proposal but also gave cogent and valuable advice on implementing the grant. In 1970 he was acting chairman of the department for six months. He has been responsible for a number of improvements in the physical plant, including a conversion of the lecture hall facilities to the system of movable tables which has become an essential element in our lecture demonstrations. He also served as chairman of the committee which made a major revision of the undergraduate physics curriculum. For the college and university he has served on the Research Council, on the Computer Science Chairmanship Search Committee, the Radiation Health and Safety Committee, and the Faculty Instructional Development Committee. At the international level he has served on the editorial board of the journal Nuclear Tracks and Radiation Measurements.

Katz's investigations into track physics stemmed naturally from his training in nuclear physics. For his thesis research and subsequently at Kansas State University, he worked in the area of nuclear spectroscopy, and taught atomic and nuclear physics. Typically at that time nuclear physics texts closed with a chapter on radiation protection in which the author dealt with the puzzling subject of the relative biological effectiveness (RBE) of high LET radiation. When subsequently he developed a model of the tracks of heavy ions in nuclear emulsions, light dawned. This was to be the basis of his model of RBE which then commanded his attention for the next 20 years. 


\section{Impact on Radiobiology}

Bob's experience with nuclear emulsions led him to postulate that biological cells would be "hit and killed" or "hit and mutated" in much the same way as photographic grains. In this he was thought to be wrong for over ten years, but has ultimately been proved spectacularly right.

Although the radiobiological community were impressed with Bob's calculated curves (for example, of RBE against LET or particle velocity or another parameter representing heavy ionization), they weren't convinced at first that the calculations could be based on an idea as simple as "one hit" (deposit of energy exceeding a threshold level) in one "target" of very small volume. His hearers always enjoyed his lectures. Indeed, he is a memorable and much respected lecturer. But originally the community felt that Bob had got the basis wrong ("a one-hit model is far too simple") and had just found a set of parameters that "happened to fit the data." There's no problem, they said, in using a one-hit model to explain the development of silver in a crystal, or of light emission from a crystal, nor even of killing dry enzymes or viruses. These are small, single crystals, so of course they fit. But, they said, that's got nothing to do with "real" radiobiology, i.e. mammalian cells. Bob was sure that his model of "ion kill" for the track and "gamma kill" for the delta rays was relevant.

It was at this exciting stage that Bob spent a sabbatical period in London, with Tikvah Alper at the MRC Radiopathology Research Unit at Hammersmith Hospital. It was for only 6 months in 1972, but featured memorable discussions with other research teams in the U.K., including ours at the Gray Laboratory a few miles away and the one at Harwell. Nobody ever forgot a lecture that Bob had given, even if he/she disagreed with him. And nobody was in doubt about what Bob was saying. The scientists now who were Ph.D. students then remember his lectures still, better than many lectures that they have heard since then. A few years after this Goodhead et al. at Harwell [Int. J. Radial. Biol. 36, 101-114 (1979)] did experiments that proved that Bob had been right in emphasizing "one hit." They generated soft Xrays from a carbon target whose photons, when absorbed in tissue, projected electrons with a range no longer than $7 \mathrm{~nm}$.
In contrast to Katz's model, the extant radiobiological dogma said that these short-range, low-energy electron tracks would be extremely inefficient, radiobiologically speaking, because the biological "targets" were believed to be as big as $200 \mathrm{~nm}$ or so. But the data showed they were just as effective as higher energy photons and electrons, so biological targets need be no bigger than $7 \mathrm{~nm}$ and the critical energy deposited in each no more than a few hundred eV. Radiobiological dogma has never been the same since. A single "hit" (track passage) is indeed all that is necessary for cell kill, for mutation, or even as a decisive step in carcinogenesis. Bob had always seen this clearly. If a single electron can deposit a certain amount of energy, above a threshold amount, in a very small volume, then the effect will occur. It is the same for delta rays surrounding a heavy particle track as for $\mathrm{X}$ - or gamma rays.

In mammalian cells there are target volumes which conceptually resemble the "single crystals" of Bob's one-hit models. They may be a few nanometers in diameter, surrounding a critical piece of DNA. The electron passing through simply has to deposit energy enough to prevent full repair of the damaged DNA. This is now the currently dominant view of the mechanism of radiation damage in biological cells; and Bob can rightly say "I told you so." And so he had, from the beginning 20 years ago, and very consistently throughout.

One of the writers of this summary (JF) got into a little trouble with the leaders in the field 26 years ago by emphasizing the effect of delta rays in radiobiology. Well, it was even more of a culture shock to have Bob saying, "But almost the whole effect is due to delta rays." And yet he has been proved right: the radius of delta rays is large enough to damage many more cells than the primary track, until doses become large enough for at least one heavy particle to pass through every cell.

So over the last decade Bob has been able to extend the applications of his radiobiological work in more detail into the areas of carcinogenesis, always with his very sound basis of measurements of the distribution of ionization as the background.

We cannot imagine Bob Katz really retiring from scientific thinking and we hope that he will go on being one of the most memorable lecturers of our generation for a long time yet. 